\title{
Systemic IFN- $\beta$ gene therapy results in long-term survival in mice with established colorectal liver metastases
}

\author{
Hiroomi Tada, ${ }^{1,2}$ David J. Maron, ${ }^{1,2}$ Eugene A. Choi, ${ }^{1,2}$ James Barsoum, ${ }^{3}$ Hanqin Lei, ${ }^{1,2}$ \\ Qing Xie, ${ }^{2}$ Wenbiao Liu, ${ }^{4}$ Lee Ellis, ${ }^{4}$ A. David Moscioni, ${ }^{2}$ John Tazelaar, ${ }^{2}$ Stephen Fawell, ${ }^{3}$ \\ Xiao Qin, ${ }^{3}$ Kathleen J. Propert, ${ }^{5}$ Alan Davis, ${ }^{2}$ Douglas L. Fraker, ${ }^{1}$ James M. Wilson, ${ }^{2}$ \\ and Francis R. Spitz ${ }^{1,2}$
}

\author{
${ }^{1}$ Department of Surgery, Division of Surgical Oncology, University of Pennsylvania Medical Center, Philadelphia, \\ Pennsylvania, USA \\ ${ }^{2}$ Institute of Human Gene Therapy, University of Pennsylvania Medical Center, Philadelphia, Pennsylvania, USA \\ ${ }^{3}$ Biogen Inc., Cambridge, Massachusetts, USA \\ ${ }^{4}$ Department of Surgery, M.D. Anderson Cancer Center, Houston, Texas, USA \\ ${ }^{5}$ Department of Biostatistics and Epidemiology, University of Pennsylvania Medical Center, Philadelphia, Pennsylvania, USA \\ Address correspondence to: Francis R. Spitz, Department of Surgery, University of Pennsylvania, \\ 4 Silverstein, 3400 Spruce Street, Philadelphia, Pennsylvania 19104, USA. \\ Phone: (215) 614-0857; Fax: (215) 662-7476; E-mail: fspitz@mail.med.upenn.edu. \\ Hiroomi Tada and David J. Maron contributed equally to this work. \\ Received for publication March 13, 2000, and accepted in revised form May 21, 2001.
}

\begin{abstract}
Most patients succumbing to colorectal cancer fail with liver-predominant metastases. To make a clinical impact in this disease, a systemic or whole-liver therapy may be required, whereas most cancer gene therapy approaches are limited in their ability to treat beyond local disease. As a preclinical model for cancer gene therapy, recombinant adenovirus containing the human IFN- $\beta$ (hIFN- $\beta$ ) cDNA was delivered systemically in nude mouse xenograft models of human colorectal cancer liver metastases. The vector targeted hepatocytes that produced high levels of hIFN- $\beta$ in the liver, resulting in a profound apoptotic response in the tumors and significant tumor regression. hIFN- $\beta$ gene therapy not only resulted in improved survival and long-term cure in a micrometastatic model, but provided similar benefits in a clinically relevant gross disease model. A similar recombinant adenovirus containing the murine IFN- $\beta$ (mIFN- $\beta$ ) cDNA also resulted in a therapeutic response and improved survival in syngeneic mouse models of colorectal cancer liver metastases. Depletion studies demonstrate a contribution of natural killer cells to this therapeutic response. The toxicity of an adenoviral vector expressing murine IFN- $\beta$ in a syngeneic model is also presented. These encouraging results warrant further investigation of the use of cancer gene therapy for targeting metastatic disease.
\end{abstract}

J. Clin. Invest. 108:83-95 (2001). DOI:10.1172/JCI200109841.

\section{Introduction}

Colorectal cancer affects more than 135,000 patients per year and is the second leading cause of cancer death in the US, accounting for over 56,000 deaths annually (1). The majority of these deaths are secondary to metastatic disease, with the liver being overwhelmingly the most common site of mestastases. For patients who are not candidates for surgical resection, prognosis and survival vary with extent of disease and performance status. The overall median survival, however, is approximately 12 months (2). Because effective therapy is unavailable, we propose to study the use of gene therapy in treating this disorder. The nature of metastatic colorectal cancer makes it well suited for in vivo gene therapy. Metastases are often isolated to the liver and are therefore readily accessible to a regional gene therapy strategy.

Recombinant adenovirus vectors have gained increasing usage in cancer gene therapy strategies. Potential advantages of adenovirus vectors include the safety of transient expression, ease of producing high titers of virus, and relatively high transduction efficiency when compared with other gene therapy vectors. Several strategies are being tested in human trials, including p53 tumor suppressor gene therapy, thymidine kinase pro-drug therapy, and oncolytic viruses (3-5). Several of these studies, which involve direct injection or instillation of vector, have demonstrated proof-of-principle and hold the potential for generating local responses $(3,6-9)$. However, the majority of patients succumbing to colorectal cancer and most solid malignancies do so secondary to systemic metastatic disease. A major hurdle in expanding the role of cancer gene therapy relates to vector transduction efficiencies and our inability to transduce a significant population of cancer cells via systemic or regional delivery.

One approach that may circumvent this limitation is a strategy that does not require high transduction of tumor cells. Systemically administered vector results in little tumor cell transduction, but primarily targets hepatocytes, which are accessible via sinusoidal fenes- 
trations $(10,11)$. We present a strategy for the treatment of colorectal cancer liver metastases using the systemic delivery of replication defective recombinant adenovirus vectors that express the hIFN- $\beta$ and the mIFN- $\beta$ gene. Transduction of these hepatocytes may result in secretion and sustained high peritumoral levels of IFN- $\beta$, which could improve the therapeutic index by minimizing systemic toxicity associated with high levels of serum IFN- $\beta$. We demonstrate that systemic delivery of adenoviral vectors expressing IFN- $\beta$ results in an antitumoral response in both mouse xenograft and syngeneic models of colorectal liver metastases.

Type I IFNs (the IFN- $\alpha$ family and IFN- $\beta$ ) are known to inhibit tumor cell growth and stimulate the immune system (12). Many investigators have demonstrated significant growth inhibition by IFN- $\beta$ of many cancers, including colorectal cancer $(13,14)$. This antiproliferative activity has been shown to be synergistic with several conventional chemotherapies $(15,16)$. Both the IFN- $\alpha$ family and IFN- $\beta$ have been demonstrated to inhibit angiogenesis and have many immunomodulatory effects (15-23). These include upregulation of MHC class I expression, increased natural killer (NK) cell activity, increased cytotoxic $\mathrm{T}$ lymphocyte activity, and enhancing the generation of T-helper cells (21-23). Unfortunately, the significant activity of the IFNs generally has not been realized in the clinical realm. These limited clinical results may be secondary to the short half-life of recombinant IFN- $\beta$ protein and the systemic toxicities of this therapy $(24,25)$. These factors make it difficult, by parental administration of protein, to attain local concentrations at which antiproliferative effects are observed. The systemic delivery of an adenovirus vector secreting IFN- $\beta$ and the resultant liver transduction may generate high local peritumoral concentrations of IFN- $\beta$ at cytostatic and cytotoxic levels, thus circumventing potential deficiencies in vector technology and recombinant IFN- $\beta$ therapy.

\section{Methods}

Cells, virus, and tissue culture. The human colorectal cell line KM12L4 was kindly obtained from I. Fidler and maintained as described previously (26). The murine colorectal cancer cell line CT26 was maintained in RPMI 1640 medium supplemented with $10 \%$ FBS. All tissue culture materials were obtained from Life Technologies Inc. (Grand Island, New York, USA), and all culture media were supplemented with $100 \mathrm{U} / \mathrm{ml}$ penicillin, 100 $\mu \mathrm{g} / \mathrm{ml}$ streptomycin, and $0.25 \mu \mathrm{g} / \mathrm{ml}$ amphotericin B.

The H5.110CMVhIFN- $\beta$ virus is an E2-deleted temperature-sensitive (TS) mutant adenovirus vector that expresses the hIFN- $\beta$ gene driven by the CMV promoter/enhancer. Its construction, characterization, and method of purification have been described elsewhere (27). The H5.110CMVmIFN- $\beta$ virus is an E2-deleted temperature-sensitive (TS) mutant adenovirus vector that expresses the murine IFN- $\beta$ gene driven by the CMV promoter/enhancer (27). The H5.010CMV $\beta$ gal virus is an E1- and E3-deleted adenovirus vector that expresses the bacterial protein $\beta$-galactosidase $(\beta$-gal) driven by the CMV promoter/enhancer (28).

Animals. Six- to 8-week-old female NCR athymic nude mice or BALB/c mice (Charles River Laboratories, Wilmington, Massachusetts, USA) and SCID-Beige mice (The Jackson Laboratories, Bar Harbor, Maine, USA) were used in protocols approved by the Institutional Review Boards of both the Wistar Institute and the University of Pennsylvania. Animals were housed in the Wistar Institute Animal Facility in sterile cages and were fed a diet of animal chow with free access to sterile water.

NK cell and macrophage depletion. NK cell depletion was performed by treatment of BALB/c mice by intraperitoneal injection $(100 \mu \mathrm{l})$ of anti-asialo GM1 antibody (1:4 dilution; Wako Chemicals USA Inc., Richmond, Virginia, USA) 2 days before, 2 days after, and on the day of tumor inoculation, as described previously (29). Macrophage depletion was achieved by administering $200 \mu \mathrm{l}$ of liposome-encapsulated DMDP via intraperitoneal injection and $100 \mu \mathrm{l}$ intravenously 2 days after tumor inoculation (30).

Intrabepatic metastatic tumor model. Our liver tumor model was developed by direct subcapsular injection of cells into the liver parenchyma. This model was used primarily in experiments in which quantitative effects on tumor size and volume were measured. KM12L4 or CT26 cells were grown in monolayers as described above. On the day of injection, cells were harvested with trypsin, washed with complete medium, and counted using the trypan blue exclusion method. Cells were resuspended in complete medium at a concentration of $1 \times 10^{6}$ cells per $100 \mu \mathrm{l}$ (KM12L4) or $1 \times 10^{4}$ cells per $50 \mu \mathrm{l}$ (CT26).

Mice were anesthetized with $10 \%$ ketamine/xylazine solution by intraperitoneal injection, and their abdomens were prepared with Betadine solution. A subcostal incision was made, and the left lobe of the liver was delivered into the wound. The left lobe was directly injected with $1 \times 10^{6} \mathrm{KM} 12 \mathrm{~L} 4$ cells or $1 \times 10^{4}$ CT2 6 cells using a 27 gauge needle, and pressure was held with a sterile cotton tip applicator until the injection site was hemostatic. The left lobe was returned to the abdominal cavity, and the incision was closed in two layers with absorbable sutures. The animals were placed on warming blankets and allowed to recover in their cages with free access to food and water. This intrahepatic injection model consistently yielded sizable tumors in $95-100 \%$ of animals.

Intrasplenic metastatic tumor model. A metastatic liver tumor model was developed for survival studies as described previously (26). On the day of injection, cells were harvested with trypsin, washed with complete medium, and counted using trypan blue exclusion. Cells were resuspended in complete medium at a concentration of $1 \times 10^{6}$ cells per $100 \mu \mathrm{l}(\mathrm{KM} 12 \mathrm{~L} 4)$ or $1 \times 10^{4}$ cells per $50 \mu \mathrm{l}(\mathrm{CT} 26)$.

Mice were anesthetized with $10 \%$ ketamine/xylazine solution by intraperitoneal injection, and their abdomens were prepared with Betadine solution. A subcostal incision was used to deliver the spleen for injection. The spleen was injected with $1 \times 10^{6} \mathrm{KM} 12 \mathrm{~L} 4$ cells or $1 \times 10^{4}$ 
CT26 cells, and pressure was held with a sterile cotton tip applicator until the injection site was hemostatic. The spleen was subsequently removed by cautery using a handheld device (Fisher Scientific Co., Pittsburgh, Pennsylvania, USA). The incision was closed in two layers with absorbable sutures, and the animals were allowed to recover. This intrasplenic injection model consistently yielded metastases in $90-95 \%$ of animals.

In vivo gene therapy: tumor measurement studies. Virus stocks were prepared as described previously and stored at $-70^{\circ} \mathrm{C}$ at a concentration of $5 \times 10^{12}$ particles per milliliter (27). Viral stocks were rapidly thawed, diluted in PBS to an appropriate concentration, and used immediately. Mice were injected by tail vein with virus in a total volume of $100 \mu$ l of PBS. All mice were randomized to different treatment groups immediately before injection with virus. After virus inoculation, the animals were returned to their cages with free access to food and water. Animals were weighed and assessed for general well-being three to four times each week for the duration of the experiment.

Liver tumors were measured 14 days after the mice received vector. Animals were euthanized by $\mathrm{CO}_{2}$ asphyxiation, and blood was collected by thoracotomy and cardiac puncture. The livers were subsequently removed intact and bisected in the horizontal plane through the middle of the tumors. The two halves were fixed in formalin overnight and stored in $70 \%$ ethanol. The tumors were subsequently measured in two planes with a caliper. and the tumor volumes were calculated assuming an ellipsoid shape. One-half of each of the tumors was subsequently embedded in paraffin, sectioned, and stained with hematoxylin and eosin. Livers that did not have any gross evidence of tumor were serially sectioned and stained to look for microscopic disease.

In situ apoptosis assays. The gross disease model described above generated specimens for the apoptosis studies. Mice were treated with vector 14 days after intrahepatic tumor inoculation. The livers were harvested from mice at 2, 5 , and 9 days after vector administration by $\mathrm{CO}_{2}$ asphyxiation. The liver tumors were bisected in the horizontal plane, fixed in $10 \%$ neutral buffered formalin for 24 hours, and then routinely processed, embedded in paraffin, and sectioned at $6 \mu \mathrm{m}$. Slides were stained with hematoxylin and eosin in standard fashion. Apoptotic cells were detected using the in situ death detection kit, Flourescein (Roche Molecular Biochemicals, Indianapolis, Indiana, USA) (31).

In vivo gene therapy survival studies. Tumor models were generated as described above. After treatment, animals were weighed three times weekly and assessed. Moribund mice were euthanized according to preestablished criteria, which were the presence of two or more of the following premorbid conditions: presence of gross ascites, palpable tumor burden greater than $2 \mathrm{~cm}$, dehydration, lethargy, emaciation, or weight loss greater than $20 \%$ of initial body weight.

Subcutaneous tumor model. Subcutaneous tumors were generated in the flanks of BALB/c mice. On the day of injection, cells were harvested with trypsin, washed with complete medium, and counted using trypan blue exclusion. Cells were resuspended in complete medium at a concentration of $1 \times 10^{4}$ cells per $50 \mu \mathrm{l}$ (CT26). Mice were anesthetized with $10 \%$ ketamine/xylazine solution by intraperitoneal injection, and their flanks were prepared with Betadine solution. $1 \times 10^{4}$ CT2 6 cells were injected. Tumors were measured twice weekly. Moribund mice were euthanized according to preestablished criteria as described above.

hIFN- $\beta$ assays. Serum hIFN- $\beta$ assays were performed by ELISA as described previously (24). Briefly, assays were performed in 96-well plates coated overnight with hIFN- $\beta$ antibody. Plates were subsequently blocked at room temperature with $1 \%$ casein in PBS for 1 hour. hIFN- $\beta$ samples and standards were added, and the samples were successively incubated with the primary and horseradish peroxidase-conjugated (HRP-conjugated) secondary antibodies and the colorimetric substrate. Absorbance was measured at $450 \mathrm{~nm}$. hIFN- $\beta$ levels are expressed as nanograms per milliliter of serum. The serum ELISA results were corroborated by a cellular cytopathic effect (CPE) assay. Briefly, the assay is based on the ability of hIFN- $\beta$ to protect A549 cells from lysis by encephalomyocarditis (EMC) virus. A549 cells were seeded into 96-well plates. hIFN- $\beta$ standards, controls, and samples were diluted in growth medium and added to the A549 wells. Fifteen to 20 hours later, EMC virus was added to the standard, controls, and sample wells and incubated for 30 hours. Separate growth control wells containing medium only were included on each plate. Crystal violet was added to all wells and incubated for 5-10 minutes. Plates were rinsed with water and allowed to dry. Results were determined by comparing the A549 cell growth in each sample well to the growth in the standard wells containing NIH standard $\beta$-IFN. Units per milliliter was determined by multiplying the dilution of the samples in the last positive well (the greatest dilution of sample that still protected the A549 cells from viral lysis) by the units per milliliter of hIFN- $\beta$ standard in the last positive standard well. With this assay, $1 \mathrm{ng}$ of protein by ELISA was equivalent to $200 \mathrm{U}$ of hIFN- $\beta$ by CPE assay.

Frozen livers were thawed and two volumes of cold PBS containing a cocktail of protease inhibitors were added to the liver. Liver was homogenized using eight strokes of a glass homogenizer. The homogenate was spun in an Eppendorf centrifuge at maximum speed. The supernatant was removed and assayed for hIFN- $\beta$ levels using the ELISA described above. hIFN- $\beta$ levels are expressed as nanograms per milliliter of original liver volume.

Immunohistochemical staining for CD31 (endothelial cells). Frozen tissues were sectioned (8-10 $\mu \mathrm{m}$ thick), mounted on positively charged slides (Fisher Scientific Co.), air dried for 30 minutes, and stored at $20^{\circ} \mathrm{C}$. The tissue was fixed in cold acetone for 5 minutes, in acetone and chloroform (1:1) for 5 minutes, and in acetone for 5 minutes. Endogenous peroxidase activity was blocked with $3 \% \mathrm{H}_{2} \mathrm{O}_{2}$. Sections were then washed with PBS (pH 7.5) and incubated in a protein-blocking solution con- 
sisting of PBS supplemented with $1 \%$ normal goat serum and $5 \%$ normal horse serum. Primary antibody to CD31 (monoclonal rat anti-mouse; PharMingen, San Diego, California, USA) was diluted in proteinblocking solution and was applied to the sections overnight at $4^{\circ} \mathrm{C}$. The next day, the sections were washed in PBS, nonspecific proteins were blocked, and an HRP-conjugated goat anti-rat IgG (Serotec Ltd., Oxford, United Kingdom) secondary antibody was added for 1 hour. Samples were then washed again and incubated with stable diaminobenzidine (DAB; Research Genetics, Huntsville, Alabama, USA). and cells were counterstained with Gill's 3 hematoxylin.

Quantification of CD31. Five random $0.159-\mathrm{mm}^{2}$ fields at $100 \times$ magnification were captured for each tumor with a Sony 3-chip camera (Sony Corp., Montvale, New Jersey, USA) mounted on a Zeiss universal microscope (Carl Zeiss, Thornwood, New York, USA) and Optimas image analysis software (Bioscan, Edmond, Washington, USA). The number of microvessels (independent CD31-positive structures) were quantified using NIH Image software (version 1.60; NIH, Bethesda, Maryland, USA), and the mean number of vessels per $0.159-\mathrm{mm}^{2}$ field was determined.

NK cytotoxicity assay. To determine NK cell activity, $\mathrm{BALB} / \mathrm{c}$ mice were sacrificed 3 days after administration of vector. Serum was harvested, and the liver and spleen from each animal were pressed through a nylon mesh and the cells were suspended in DMEM containing 2.5 mM EDTA (Life Technologies Inc.) and $3 \mathrm{U} / \mathrm{ml}$ Heparin (Elkins-Sinn Inc., Philadelphia, Pennsylvania, USA). The liver suspension was mixed with $33 \%$ Percoll (Amersham Pharmacia Biotech, Piscataway, New Jersey, USA) and centrifuged at $1,000 \mathrm{~g}$ for 10 minutes to remove liver parenchymal cells. Both the liver and spleen suspensions were then washed twice with PBS and combined. The mononuclear cell fraction was obtained by a Ficoll (Amersham Pharmacia Biotech) separation gradient. The mononuclear cells were incubated with anti-NK cell (DX5) antibody-coated magnetic microbeads (Miltenyi Biotec, Auburn, California, USA) and passed through a separation column to isolate the NK cells. NK cells were then cultured in RPMI 1640 (Life Technologies Inc.) supplemented with $12.5 \%$ filtered serum from the sacrificed animals, $100 \mathrm{U} / \mathrm{ml}$ penicillin, and $100 \mu \mathrm{g} / \mathrm{ml}$ streptomycin in a $5 \% \mathrm{CO}_{2}$ incubator at $37^{\circ} \mathrm{C}$ for 48 hours.

NK cell activity was determined using a ${ }^{51}$ chromiumrelease assay as described previously (32). Briefly, $1 \times 10^{6}$ YAC-1 mouse lymphoma cells (American Type Culture Collection, Rockville, Maryland, USA) were radiolabeled with $100 \mu \mathrm{Ci}$ of sodium chromate $\left({ }^{51} \mathrm{Cr}\right.$ ) (Amersham Pharmacia Biotech) in $500 \mu \mathrm{l}$ of RPMI 1640 at $37^{\circ} \mathrm{C}$ for 2 hours. The cells were then washed twice with PBS and diluted to $1 \times 10^{4}$ cells per $100 \mu$ l. Effector cells (NK cells) were added at various effector/target ratios, and a final volume of $100 \mu \mathrm{l}$ was added to the wells of a U-shaped 96well plate. The reaction was incubated at $37^{\circ} \mathrm{C}$ for 4 hours. The 96-well plate was then centrifuged, and the ${ }^{51} \mathrm{Cr}$ release from $100 \mu \mathrm{l}$ of supernatant was counted in a liquid scintillation counter. The percentage of cytotoxicity was calculated as (Experimental release - Spontaneous release $) /($ Total release - Spontaneous release $) \times 100$, where the spontaneous release is the release of ${ }^{51} \mathrm{Cr}$ from nonlabeled cells, and total release is the release of ${ }^{51} \mathrm{Cr}$ from labeled cells lysed with $1 \%$ Triton-X (Sigma Chemical Co., St. Louis, Missouri, USA).

Histopathological analysis of livers. Histopathological analysis was performed by independent pathologists (Experimental Pathology Labs Inc., Herndon, Pennsylvania, USA) blinded to treatment.

Statistical analysis. For the tumor volume data, Kruskal-Wallis tests were performed to test the effect of treatment on total volume. For the survival data, logrank tests were performed to test the effect of treatment, and Kaplan-Meier curves were plotted. $P<0.05$ was considered significant.

\section{Results}

hIFN- $\beta$ gene therapy is effective in a microscopic liver metastases model. The construction of a replication-defective, E1 deleted, temperature-sensitive mutant E2a adenovirus vector expressing the hIFN- $\beta$ gene, driven by the cytomegalovirus (CMV) promoter/enhancer (H5.110CMVhIFN- $\beta$ ) has been previously reported (27). We evaluated this vector in a clinically relevant in vivo nude mouse xenograft model for liver metastases. In a micrometastatic model, nude mice were inoculated intrahepatically with a human colorectal cancer cell line (KM12L4; kindly provided by I. Fidler, M.D. Anderson Cancer Center). The mice were treated with systemically administered vector 5 days after tumor inoculation. This time point was chosen following modeling experiments that demonstrated microscopic disease at 5 days after tumor inoculation (data not shown). Animals were euthanized 19 days after cancer cell inoculation, and tumors were measured. As has been observed by other investigators, marker studies in tumor bearing mice administered H5.010CMV $\beta$-gal via tail vein demonstrated significant hepatocyte transduction, but essentially no tumor cell transduction (data not shown) (10, 11). Although treatment with control vector resulted in a modest reduction in tumor size, a profound effect was observed in the H5.110CMVhIFN- $\beta$-treated mice (Figure 1a). In fact, in nine of the ten mice treated with H5.110CMVhIFN- $\beta$, there was no histological evidence of residual cancer cells within the liver.

We next performed a dose-escalation experiment to determine the dose of vector required to demonstrate a therapeutic effect in the nude mouse micrometastatic model. H5.110CMVhIFN- $\beta$ was systemically delivered at doses of $1 \times 10^{10}, 2.5 \times 10^{10}, 5 \times 10^{10}$, and $1 \times 10^{11}$ particles per mouse. Significant reductions in tumor volumes were observed at all doses delivered (Figure 1b). Additionally, a dose response was observed, with lower doses resulting in decreased tumor size but not complete elimination of tumors. In contrast, the higher doses of vector resulted in many animals with complete elimination of microscopic evidence of tumor cells within the liver. 

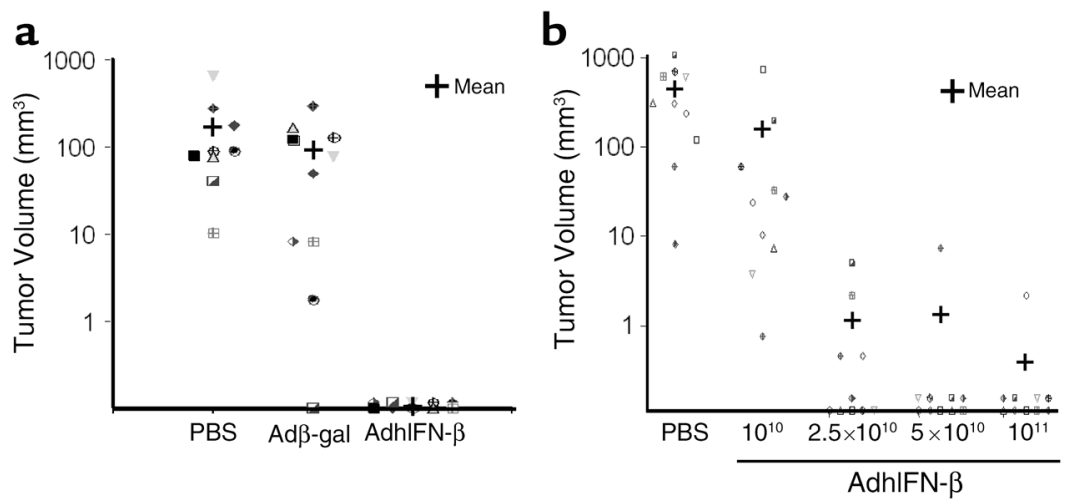

C

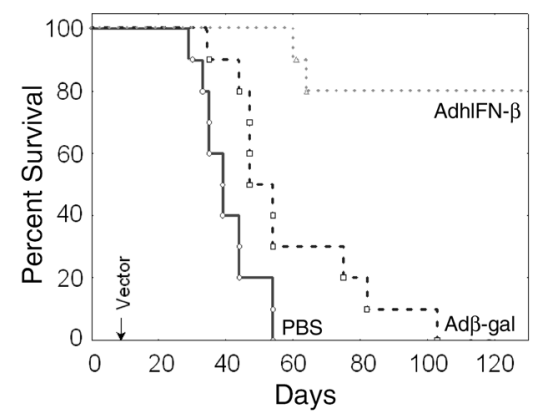

\section{Figure 1}

H5.110CMVhIFN- $\beta$ treatment inhibits growth of human colon cancer cells in a dose-dependent fashion in an intrahepatic microscopic disease athymic nude mouse liver metastases model and improves survival in an intrasplenic microscopic disease athymic nude mouse liver metastases model. (a) KM12L4 cells were directly injected into the livers of athymic nude mice. On day 5, mice were randomized to receive PBS, H5.010CMV $\beta$-gal (Ad $\beta$-gal), or H5.110CMVhIFN- $\beta$ (AdhIFN- $\beta$ ) via tail vein injection. On day 19 , animals were sacrificed and livers were harvested for tumor volume measurement. Each point represents a single animal. Mean tumor volume is indicated by the large cross. $(P=0.0001$. $)$ One animal in the PBS group died on day 17 of diffuse metastasis and was not included in the final average. (b) KM12L4 cells were injected as described above. On day 5, mice were randomized to receive PBS or H5.110CMVhIFN. Animals were sacrificed on day 19 and the livers harvested for tumor volume measurement. $(P<0.0001$. $)(\mathbf{c}) \mathrm{KM} 12 \mathrm{~L} 4$ cells were directly injected in the spleens of athymic nude mice followed by splenectomy. On day 5, mice were randomized to receive PBS, H5.010CMV $\beta$-gal, or H5.110CMVhIFN- $\beta$ via tail vein injection. Mice were sacrificed when they became moribund by preestablished criteria, and their survival curves were plotted.

Nine of ten animals were histologically free of tumor at both the $5 \times 10^{10}$ and $1 \times 10^{11}$ particle dose.

To correlate tumor responses with IFN levels, we measured serum and hepatic levels of hIFN- $\beta$ in non-tumor bearing mice treated with the same doseescalation schedule. At lower doses of vector $\left(1 \times 10^{10}\right.$ and $\left.2.5 \times 10^{10}\right)$, measurable levels of interferon were evident in the liver, and low or undetectable levels of interferon were observed systemically (Table 1). At higher doses of vector, $5 \times 10^{10}$ and $1 \times 10^{11}$, both systemic and hepatic levels of hIFN- $\beta$ were detectable.

Survival studies were performed to evaluate whether the tumor response observed in vivo could translate into a survival benefit. Although the intrahepatic model enables accurate measure of tumor sizes, this model could potentially result in artificial results secondary to trauma at the injection site, subsequent inflammation, or altered angiogenesis. Therefore, we evaluated an intrasplenic microscopic disease model in the survival studies. The intrasplenic model results in multiple liver metastases via access from the portal sys- tem, which more closely mirrors the clinical situation. Nude mice were treated with vector administration 5 days after tumor inoculation. Treatment with H5.110CMVhIFN- $\beta$ resulted in a profound and statistically significant improvement in survival of treated animals (Figure 1c). Seven of ten animals treated with H5.110CMVhIFN- $\beta$ were alive with no clinical evidence of disease more than 130 days after tumor cell inoculation, whereas all the control animals died. Median survival for the PBS group was 39 days, and median survival for the H5.010CMVßgal-treated group was 47 days. Median survival has not been reached in the H5.110CMVhIFN- $\beta$-treated group $(P<0.0001)$.

Mice with measurable tumor burdens respond to bIFN- $\beta$ gene therapy. Having demonstrated in vivo efficacy in our model, we moved to a gross disease model that may have clinical relevance to the treatment of patients who present with metastatic disease. This model also enabled us to evaluate the response of tumor cells in vivo to this therapy. Adenoviral vector was delivered systemically to nude mice 14 days after tumor cell inoculation (intra-

Table 1

Systemic delivery of H5.110CMVhIFN- $\beta$ results in sustained hIFN- $\beta$ levels in the liver and serum of nude mice

\begin{tabular}{|c|c|c|c|c|c|c|c|}
\hline \multirow[b]{2}{*}{ Treatment } & \multirow[b]{2}{*}{ Dose (particles per animal) } & \multicolumn{3}{|c|}{ Serum hIFN- $\beta$ levels $(\mathrm{ng} / \mathrm{ml})$} & \multicolumn{3}{|c|}{ Liver hIFN- $\beta$ levels $(\mathrm{ng} / \mathrm{ml})$} \\
\hline & & Day 3 & Day 7 & Day 14 & Day 3 & Day 7 & Day 14 \\
\hline $\begin{array}{l}\text { PBS } \\
\text { H5.110CMVhIFN- } \beta \\
\text { H5.110CMVhIFN- } \beta \\
\text { H5.110CMVhIFN- } \beta\end{array}$ & $\begin{array}{c}- \\
1.0 \times 10^{10} \\
2.5 \times 10^{10} \\
5.0 \times 10^{10}\end{array}$ & $\begin{aligned} & <3 \\
& <3 \\
19.3 & (14.8) \\
333.4 & (178.3)\end{aligned}$ & $\begin{array}{c}<3 \\
4.0^{\mathrm{A}}(2.1) \\
10.1^{\mathrm{A}}(7.5) \\
69.5(22.1)\end{array}$ & $\begin{array}{c}<3 \\
7.8^{A}(10.5) \\
7.8^{A}(7.0) \\
44.4(29.5)\end{array}$ & $\begin{array}{c}<9 \\
13.3(3.0) \\
27.9(12.7) \\
158.8(64.3)\end{array}$ & $\begin{array}{c}<9 \\
20.6(3.1) \\
19.1(4.5) \\
49.2(32.2)\end{array}$ & $\begin{array}{c}<9 \\
21.7(13.8) \\
20.1(7.9) \\
18.5(18.4)\end{array}$ \\
\hline H5.110CMVhIFN- $\beta$ & $1.0 \times 10^{11}$ & $228.9(126.4)$ & $323.2(48.5)$ & $181.6(84.2)$ & $115.3(15.7)$ & $81.8(34.9)$ & $44.2(27.1)$ \\
\hline
\end{tabular}

$n=4$ per group (SD). Level of detection was $3 \mathrm{ng} / \mathrm{ml}$ for serum samples. Liver homogenates were diluted 3:1 before assay, so the minimum detectable level was $9 \mathrm{ng} / \mathrm{ml}$. ${ }^{A} \mathrm{~A}$ set in which one or more samples were undetectable. 


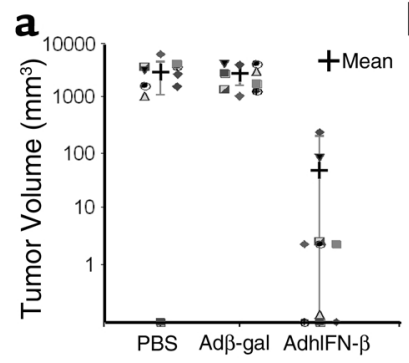

b

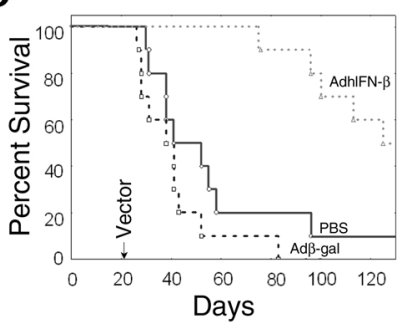

Figure 2

H5.110CMVhIFN- $\beta$ inhibits the growth of established human colorectal cancer cell line tumors in an intrahepatic athymic nude mouse model for liver metastases and improves survival in an intrasplenic gross disease athymic nude mouse xenograft model of colorectal liver metastasis. (a) KM12L4 cells were directly injected in the livers of athymic nude mice. On day 14 , when tumors were 3-5 $\mathrm{mm}^{3}$, animals were randomized to receive PBS, H5.010CMV $\beta$-gal, or $\mathrm{H} 5.110 \mathrm{CMVhIFN}-\beta$ via tail vein injection. On day 28 animals were sacrificed and sera and livers were harvested for tumor volume measurement. Each point represents a single animal. Mean tumor size is indicated by the large cross. Bars $=\mathrm{SE} .(P<0.0001$. $)($ b) $\mathrm{KM} 12 \mathrm{~L} 4$ cells were injected in the spleens of athymic nude mice followed by splenectomy. On day 21 , mice were randomized to receive PBS, H5.010CMV $\beta$-gal, or H5.110CMVhIFN- $\beta$ via tail vein injection. Mice were sacrificed when they became moribund by preestablished criteria, and their survival curves were plotted.

hepatic). Previous tumor modeling experiments had demonstrated the appearance of measurable tumors of $3-5 \mathrm{~mm}$ in diameter 14 days after tumor inoculation (data not shown). A significant reduction in tumor size was observed in mice treated with the systemic administration of H5.110CMVhIFN- $\beta$ compared with control vector and PBS control (Figure 2a). Tumor sizes in the H5.110CMVhIFN- $\beta$-treated group represent not only decreased tumor growth, but also tumor regression. Nine of ten animals in the PBS-treated group, and all the animals in the H5.010CMV $\beta$ gal-treated group, developed very large tumors $\left(>1,000 \mathrm{~mm}^{3}\right)$. In contrast, four animals in the H5.110CMVhIFN- $\beta$-treated group had no histological evidence of tumor, and another four had tumors of $1 \mathrm{~mm}^{3}$ or less.

In a most challenging model, we evaluated the potential survival benefit of H5.110CMVhIFN- $\beta$ therapy on mice with multiple gross liver metastases treated with systemic administration of vector 21 days after intrasplenic tumor inoculation. In this model, untreated mice can become moribund as early as 28 days after tumor inoculation. Again, a significant improvement in survival was observed in animals treated with systemic H5.110CMVhIFN- $\beta$ (Figure 2b). Median survival for the PBS and H5.010CMV $\beta$ gal-treated groups were 41 days and 36 days, respectively. Median survival for the H5.110CMVhIFN- $\beta$-treated group was 120 days $(P<0.0001)$. Five animals were alive and functioning well without clinical evidence of tumor more than 130 days after treatment. Three animals in the H5.110CMVhIFN$\beta$ treatment group failed with extrahepatic disease (in intra-abdominal and cervical lymph nodes) but showed no evidence of either gross or microscopic liver involvement at the time they were euthanized. Two animals died with both systemic and hepatic disease.

Local bIFN- $\beta$ expression induces apoptosis in established tumors. To delineate the direct effects of hIFN- $\beta$ on the human colorectal tumors, we evaluated tumors 2, 5, and 9 days after treatment in the gross disease model (Figure 3). Histologically, an apoptotic response was observed in the H5.110CMVhIFN- $\beta$-treated tumors compared with control vector and PBS. These effects were observed early, at 2 and 5 days after treatment. By the 9th day after treatment, most of the residual tissue in the tumor site was cellular debris. An apoptotic response in the tumor cells was confirmed by in situ TUNEL of the specimens. Again, at 2 and 5 days after vector administration, the majority of tumor cells showed evidence of TUNEL labeling consistent with induction of apoptosis.

IFN- $\beta$-induced apoptosis in a colorectal cancer cell line is associated with induction of the Jak-Stat pathway and the proapoptotic mediators Bak and TNF-related apoptosis-inducing ligand. After demonstrating a significant apoptotic response in vivo, we sought to evaluate this process in vitro. In vitro analysis was performed to evaluate the induction of the Jak-Stat pathway and the mitochondrial and cell surface pathways of apoptosis after H5.110CMVhIFN- $\beta$ treatment. Treatment of KM12L4 cells in vitro with H5.110CMVhIFN- $\beta$ was associated with decreased cell survival and induction of apoptosis as measured by in situ TUNEL staining, histone release measured by cell death detection ELISA (Roche Molecular Biochemicals), and Parp cleavage demonstrated by Western blot analysis (Figure 4a).

Table 2

Intraperitoneal delivery of recombinant hIFN- $\beta$ results in 1-hour peak hIFN- $\beta$ levels in the liver and serum of nude mice

\begin{tabular}{|c|c|c|c|c|c|c|c|c|}
\hline \multirow[b]{2}{*}{ Treatment } & \multicolumn{4}{|c|}{ Serum hIFN- $\beta$ levels (ng/ml) } & \multicolumn{4}{|c|}{ Liver hIFN- $\beta$ levels (ng/ml) } \\
\hline & 5 minutes & 30 minutes & 1 hour & 6 hours & 5 minutes & 30 minutes & 1 hour & 6 hours \\
\hline PBS & $<3$ & $<3$ & $<3$ & $<3$ & $<9$ & $<9$ & $<9$ & $<9$ \\
\hline $\begin{array}{l}1,000 \cup \text { recombinant } \\
\text { hIFN- } \beta \text { intraperitoneally }\end{array}$ & $<3$ & $<3$ & $<3$ & $<3$ & $<9$ & $<9$ & $<9$ & $<9$ \\
\hline $\begin{array}{l}10,000 \cup \text { recombinant } \\
\text { hIFN- } \beta \text { intraperitoneally }\end{array}$ & $19.2^{\mathrm{A}}(10.4)$ & $54.4(8.0)$ & $90.5(40.1)$ & $<3$ & $12.8^{A}(6.9)$ & $40.9(5.4)$ & $64.2(27.4)$ & $<9$ \\
\hline
\end{tabular}

$n=4$ per group (SD). Level of detection was $3 \mathrm{ng} / \mathrm{ml}$ for serum samples. Liver homogenates were diluted 3:1 before assay, so the minimum detectable level was $9 \mathrm{ng} / \mathrm{ml}$. ${ }^{A} \mathrm{~A}$ set in which one or more samples were undetectable. 
Western and Northern blot analyses of the KM12L4 cells after H5.110CMVhIFN- $\beta$ treatment were then performed to evaluate the contribution of the Jak-Stat signaling pathway. Increased expression of the ISGF3 transcription complex members Stat1, Stat2, and ISGF3 $\gamma$, along with IRF1, was observed after H5.110CMVhIFN- $\beta$ infection (Figure $4 \mathrm{~b}$ ), indicating activation of this pathway after IFN- $\beta$ treatment.

We evaluated changes in apoptosis-related molecules after in vitro H5.110CMVhIFN- $\beta$ treatment of KM12L4 cells with Western blot analysis and RiboQuant multiprobe RNase protection assay (PharMingen). Analysis of the Bcl-2 family of proteins demonstrated increases in the proapoptotic Bak mRNA and protein levels after treatment (Figure 4c).

RiboQuant multiprobe RNase protection assay was also used to evaluate changes in mRNA transcripts of death receptor pathway related molecules after H5.110CMVhIFN- $\beta$ treatment of KM12L4 cells. As demonstrated in Figure 4d, a 22-fold increase in TNF-related apoptosis-inducing ligand (TRAIL) was observed after treatment. The induction of TRAIL and Bak by IFN- $\beta$ represent potential mechanisms by which this apoptotic process is induced.

Recombinant bIFN- $\beta$ protein therapy fails to produce a therapentic response. In this liver metastases model, we evaluated the ability of recombinant hIFN- $\beta$ protein therapy to engender a therapeutic response in both the microscopic and gross disease models. Recombinant hIFN- $\beta$ protein was delivered by intraperitoneal injection to nude mice 5 (microscopic) or 14 (gross disease) days after tumor cell inoculation (intrahepatic). Group 1 was treated with PBS; group 2 with $1,000 \mathrm{U}$ of hIFN- $\beta$ daily for 14 days; and group 3 was treated with 10,000 U of hIFN- $\beta$ daily for 14 days. Mice were euthanized 14 days after initiation of recombinant hIFN- $\beta$ protein therapy. As demonstrated in Figure 5, a and $b$, minimal reductions in tumor size were observed after treatment with either dose of recombinant hIFN- $\beta$ in either model.

To determine the kinetics of recombinant IFN- $\beta$ administration in this model, serum and liver hIFN- $\beta$ levels were measured after administration of 1,000 or $10,000 \mathrm{U}$ of recombinant hIFN- $\beta$ protein. As demonstrated in Table 2 , peak serum levels were observed at 1 hour after administration of $10,000 \mathrm{U}$ of recombinant hIFN- $\beta$ protein. These were within the range observed after low-dose administration of H5.110CMVhIFN- $\beta$; however, they fell to below the level of detection in less than 6 hours after protein administration. Hepatic levels of IFN- $\beta$ were slightly lower than serum levels after protein administration at all time points. At the $1,000 \mathrm{U}$ dose, levels of IFN- $\beta$ were below the level of detection in either the serum or the liver.
bIFN- $\beta$ gene therapy is not effective in a murine colorectal cancer liver metastases model. Because IFN- $\beta$ is known to have significant species specificity, we suspected that the significant tumor regression and apoptosis after H5.110CMVmIFN- $\beta$ treatment was secondary to the direct effects of hIFN- $\beta$ on the human colorectal cancer cells rather than secondary effects related to the environment surrounding the tumor. We therefore evaluated the response of a murine colorectal cancer cell line (CT26) in this model to delineate this mechanism further. Five days after intrahepatic injection with
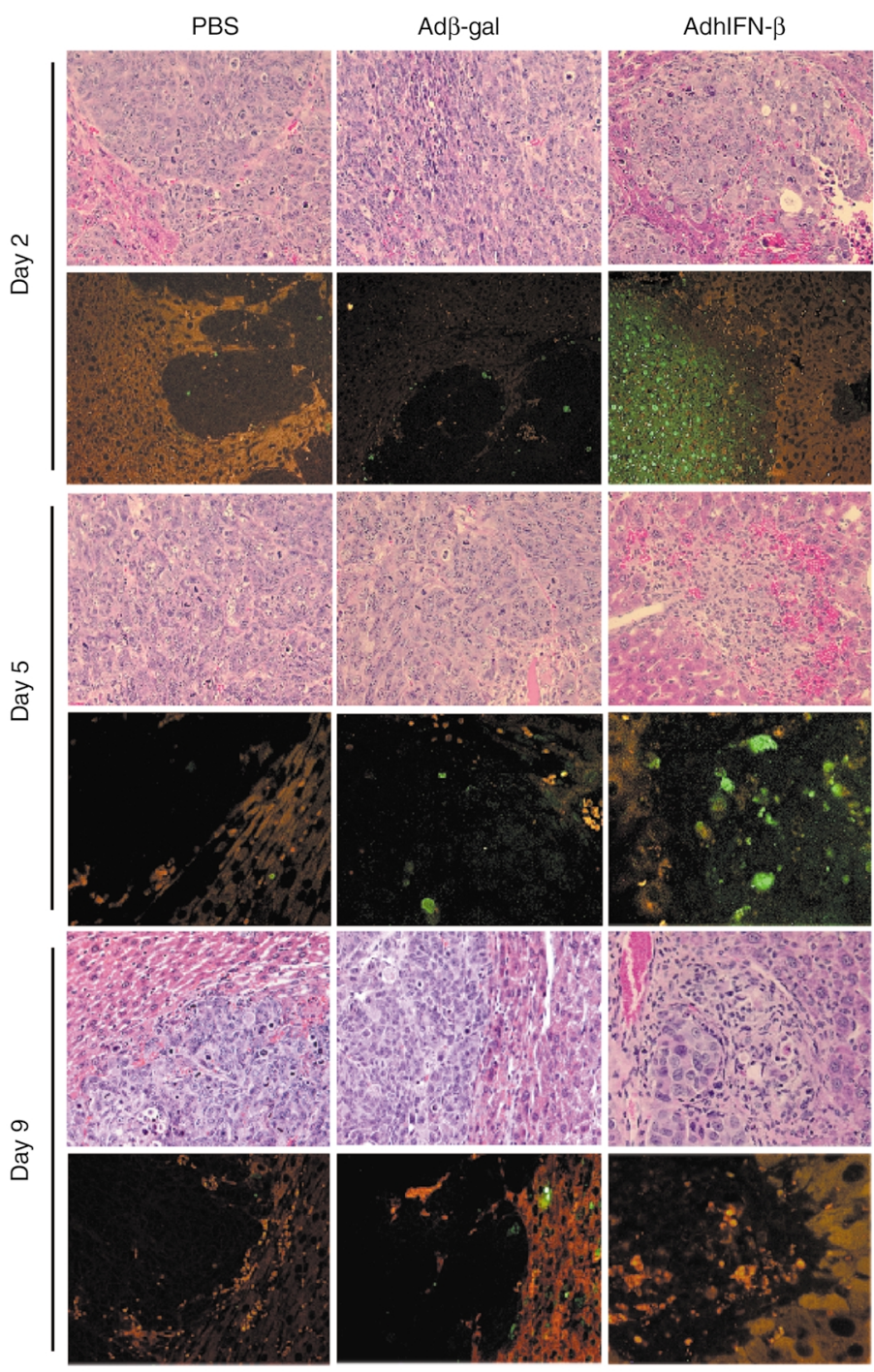

\section{Figure 3}

H5.110CMVhIFN- $\beta$ treatment results in induction of apoptosis in established human colorectal cancer cell line tumors in an athymic nude mouse model for liver metastases. KM12L4 cells were directly injected in the livers of athymic nude mice. On day 14 , when tumors were $3-5 \mathrm{~mm}^{3}$, animals were randomized to receive PBS, $\mathrm{H} 5.010 \mathrm{CMV} \beta$-gal, or $\mathrm{H} 5.110 \mathrm{CMVhIFN}-\beta$ via tail vein injection. Three animals per group were sacrificed 2, 5, and 9 days after vector administration. The liver tumors were bisected in the horizontal plane and fixed in $10 \%$ neutral buffered formalin for 24 hours, then routinely processed, embedded in paraffin, and sectioned at $6 \mu \mathrm{m}$. Slides were stained with hematoxylin and eosin in standard fashion. Apoptotic cells were detected using the in situ death detection kit Flourescein (Roche Molecular Biochemicals). 

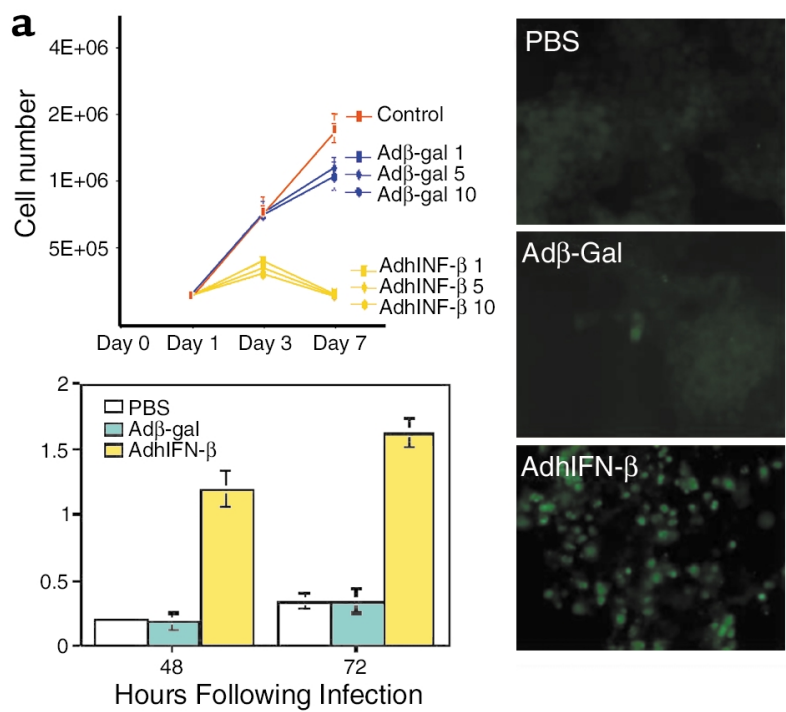

Hours Following Infection

\section{Figure 4}

IFN- $\beta$-induced apoptosis is associated with induction of the Jak-Stat pathway and the proapoptotic mediators Bak and TRAIL. (a) Upper left panel: Cell counts. Lower left panel: Cell death detection ELISA. Right panel: In situ TUNEL staining. (b) Western blot and Northern analyses of downstream mediators of IFN- $\beta /$ receptor binding. Protein immunoblot analysis of signal transducers and activators of transcription (Stat) proteins, Stat1, Stat2, and ISGF3 $\gamma$, in whole cell extracts from colorectal cell line KM12L4 48 hours after treatment with PBS, Ad $\beta$-gal, or AdhIFN- $\beta$ (10 pfu). RNA analysis of Stat 1 , Stat 2 , ISGF3 $\gamma$, and IRF1 in treated KM12L4 cells 48 hours after treatment. Equal loading of mRNA is demonstrated on Northern blot by GADPH. (c) Protein immunoblot analysis of Waf1, bcl-2, bcl-X, bak, and bax in whole cell extracts $(50 \mathrm{mg})$ from colorectal cell line KM12L4 48 hours after treatment. Messenger RNA analysis of colorectal cell line KM12L4 48 hours after treatment for the bcl-2 family apoptosis-related genes using the multiprobe RNase Protection Assay (RPA) system. Gel band intensities were quantified with the UN-Scan-It program (Silk Scientific Corp., Orem, Utah, USA) and presented as ratio of AdhIFN- $\beta /$ PBS band intensity after normalization with the housekeeping gene L32. (d) Messenger RNA analysis of the colorectal cell line KM12L4 48 hours after treatment for the death receptor family apoptosis-related genes using the multiprobe RPA system. Gel band intensities were quantified with the UN-Scan-It program and presented as ratio of AdhIFN- $\beta /$ PBS band intensity after normalization with the housekeeping gene L32. b

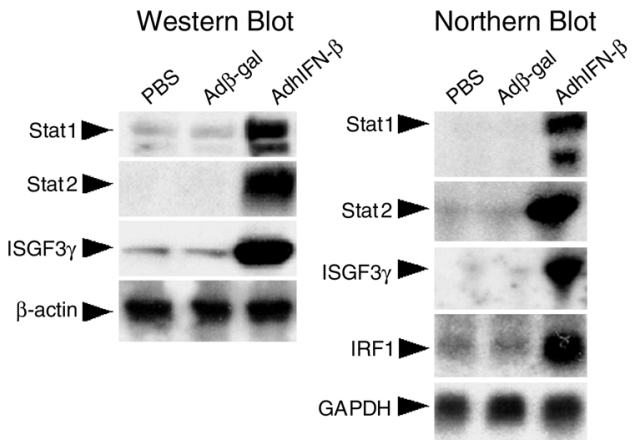

C
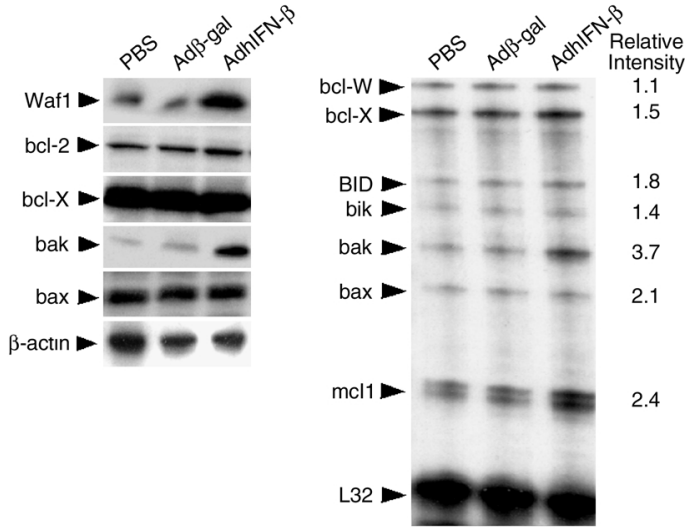

2.4

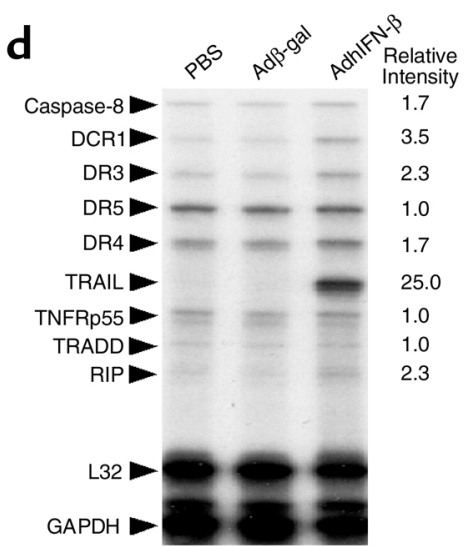

CT26 cells, athymic nude mice were treated with systemic administration of PBS, H5.010CMV $\beta$-gal, or H5.110CMVhIFN- $\beta$. Animals were euthanized 19 days after cancer cell inoculation, and tumors were measured. Consistent with our hypothesis, no significant difference in tumor size was observed between animals treated with H5.110CMVhIFN- $\beta$ compared with those treated with PBS or vector control (Figure 6a).

Toxicity associated with vector administration. The systemic administration of recombinant adenoviral vectors and subsequent hepatocyte transduction may result in inflammation and potential toxicity to the liver. Additionally, the expression of IFN- $\beta$ may result in hepatic and/or systemic toxicities. Because of species specificity, it is unlikely that hIFN- $\beta$ would result in significant toxicity related to human IFN- $\beta$-induced effects in a mouse. Therefore, in an effort to evaluate the toxicity of this adenovirus-mediated gene therapy along with toxicity related to the IFN- $\beta$ transgene, we evaluated the toxicity of a recombinant adenovirus that expresses murine IFN- $\beta$ (H5.110CMVmIFN- $\beta$ ) in immune-competent mice. BALB/c mice were administered PBS, H5.110CMVmIFN- $\beta$, or control vector (H5.110CMVhOTC) at doses of $1 \times 10^{10}, 3 \times 10^{10}$, and $1 \times 10^{11}$ particles per mouse. Animals were evaluated 3 , 7,14 , and 28 days after vector administration by necropsy (five animals per group per time point). Serum alanine transaminase levels (ALTs) were measured, and histopathological analysis was performed by independent pathologists (Experimental Pathology Labs Inc., Herndon, Pennsylvania, USA) blinded to treatment. Elevations in ALTs were observed in a dosedependent fashion after treatment with the adenoviral vectors (Figure 7a). Elevations were greatest in the control vector (H5.110CMVhOTC) group treated with $1 \times 10^{11}$ particles per mouse. The elevations in this group peaked at $7-14$ days after vector administration and were close to baseline by 28 days after vector 

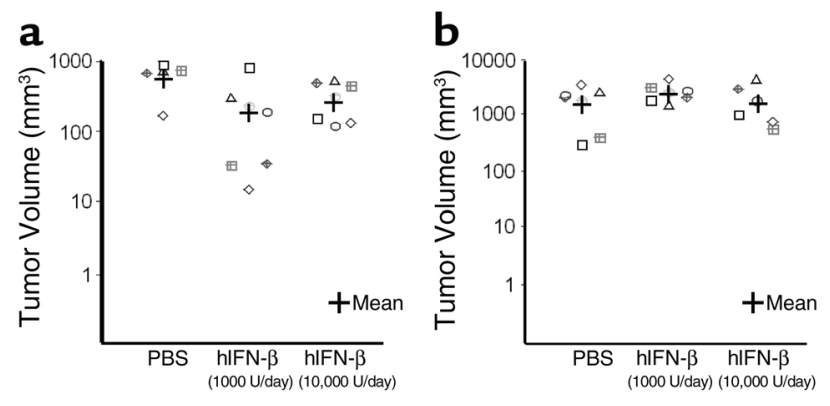

\section{Figure 5}

Recombinant IFN- $\beta$ protein therapy does not result in a significant tumor response. (a) KM12L4 cells were directly injected in the livers of athymic nude mice. On day 5 , when tumors were microscopic, animals were randomized to receive daily intraperitoneal injections of PBS or recombinant hIFN- $\beta$ (1,000 U or 10,000 U). On day 28 animals were sacrificed and sera and livers were harvested for tumor volume measurement. (b) On day 14 , when tumors were 3-5 $\mathrm{mm}^{3}$, animals were randomized to receive daily intraperitoneal injections of PBS or recombinant hIFN- $\beta(1,000 U$ or $10,000 U)$. On day 28 animals were sacrificed and sera and livers were harvested for tumor volume measurement. Each point represents a single animal, and mean tumor volume is indicated by the large cross.

administration. The changes observed in ALTs after vector administration were less prominent in animals treated with H5.110CMVmIFN- $\beta$.

Histopathological changes in the liver were also observed in a dose-dependent fashion and were most prominent 7 and 14 days after administration of the control vector (Figure $7 \mathrm{~b}$ ). These included inflammatory changes, hepatocytomegaly, increased mitosis, and hepatocyte degeneration. These changes were less promi- nent and approaching baseline by 28 days after vector administration. Administration of H5.110CMVmIFN- $\beta$ resulted in less prominent inflammatory changes in the liver compared with control vector. However, hepatocyte vacuolization was observed in the animals administered the $1 \times 10^{11}$ particles per mouse dose. Significantly, there was apparent systemic toxicity in animals administered $1 \times 10^{11}$ particles of H5.110CMVmIFN- $\beta$ per mouse. Two of five animals from the 28 -day time point suffered mortalities. These were associated with tissue edema, peritoneal fluid, and pleural fluid at necropsy. Histopathological evaluation of the livers as discussed above demonstrated few changes; however, histopathological evaluation of the kidneys demonstrated evidence of glomerulonephropathy. In summary, inflammatory changes in the liver and elevations in ALTs were less prominent in mice administered H5.110CMVmIFN- $\beta$ compared with control vector; however, systemic toxicities were observed at a dose of $1 \times 10^{11}$ particles per mouse of H5.110CMVmIFN- $\beta$.

mIFN- $\beta$ gene therapy is effective in a murine colorectal cancer liver metastases model. Our data with human colorectal cancer cell lines in nude mice demonstrate the potential of adenovirus-mediated hIFN- $\beta$ gene therapy against metastatic colorectal cancer. However, it is possible that in humans, the antiviral activity of hIFN- $\beta$ along with the immune response to the adenoviral vector may limit gene expression and therefore efficacy. We therefore evaluated the effects of an adenovirus that expresses murine IFN- $\beta$ (H5.110CMVmIFN- $\beta$ ) in a syngeneic immune-competent metastatic colorectal model. BALB/c mice were inoculated with the syngeneic colorectal cancer cell line CT26 by intrahepatic injection. This cell line is relatively resistant

\section{Figure 6}

H5.110CMVhIFN- $\beta$ treatment does not inhibit the growth of a murine colorectal cell line in an intrahepatic microscopic disease athymic nude mouse liver metastases model; however, H5.110CMVmIFN- $\beta$, which expresses murine IFN- $\beta$, inhibits the growth of murine colorectal liver tumors and improves survival in a liver metastases model. (a) CT26 cells were directly injected in the livers of athymic nude mice. On day 5 , mice were randomized to receive PBS, $\mathrm{H} 5.010 \mathrm{CMV} \beta$-gal, or H5.110CMVhIFN- $\beta$ via tail vein injection. On day 19, livers were harvested for tumor volume measurement. Each point represents a single animal, and mean tumor volume is indicated by the large cross. (b) CT26 cells were injected directly in the livers of BALB/C mice. On day 5 , mice were randomized to receive PBS, $\mathrm{H} 5.010 \mathrm{CMV} \beta$-gal, or H5.110CMVmIFN- $\beta$ (AdmIFN- $\beta$ ) via tail vein injection. On day 19 , livers were harvested for tumor volume measurement $(P=0.0001)$. (c) CT26 cells were injected into the spleens of BALB/c mice. On day 5 , mice were randomized to receive PBS, H5.010CMV $\beta$-gal, or $\mathrm{H} 5.110 \mathrm{CMVmIFN}-\beta$ via tail vein injection, or daily intraperitoneal injections of $10,000 \mathrm{U}$ of recombinant mIFN- $\beta$ protein. Mice were sacrificed when they became moribund by preestablished criteria, and their survival curves were plotted. (d) CT26 cells were injected subcutaneously into the flanks of BALB/c mice. On day 5 , mice were randomized to receive PBS, H5.010CMV $\beta$-gal, or H5.110CMVmIFN- $\beta$ via tail vein injection. Tumors were measured twice per week and tumor volumes were estimated assuming an ellipsoid shape $(P<0.05)$.
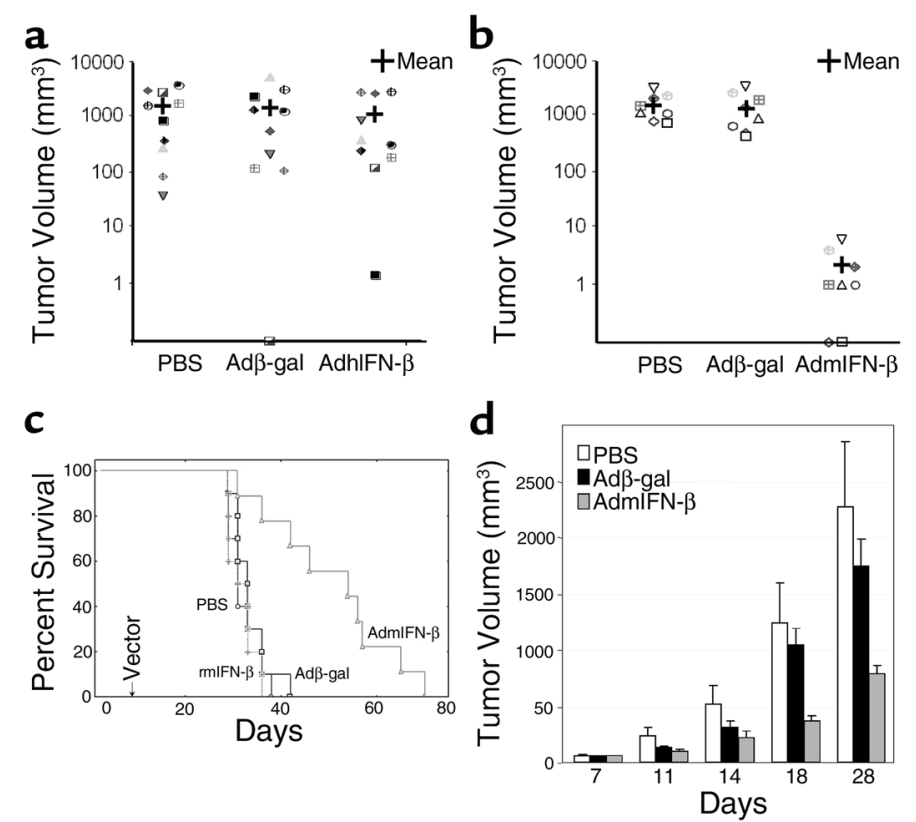

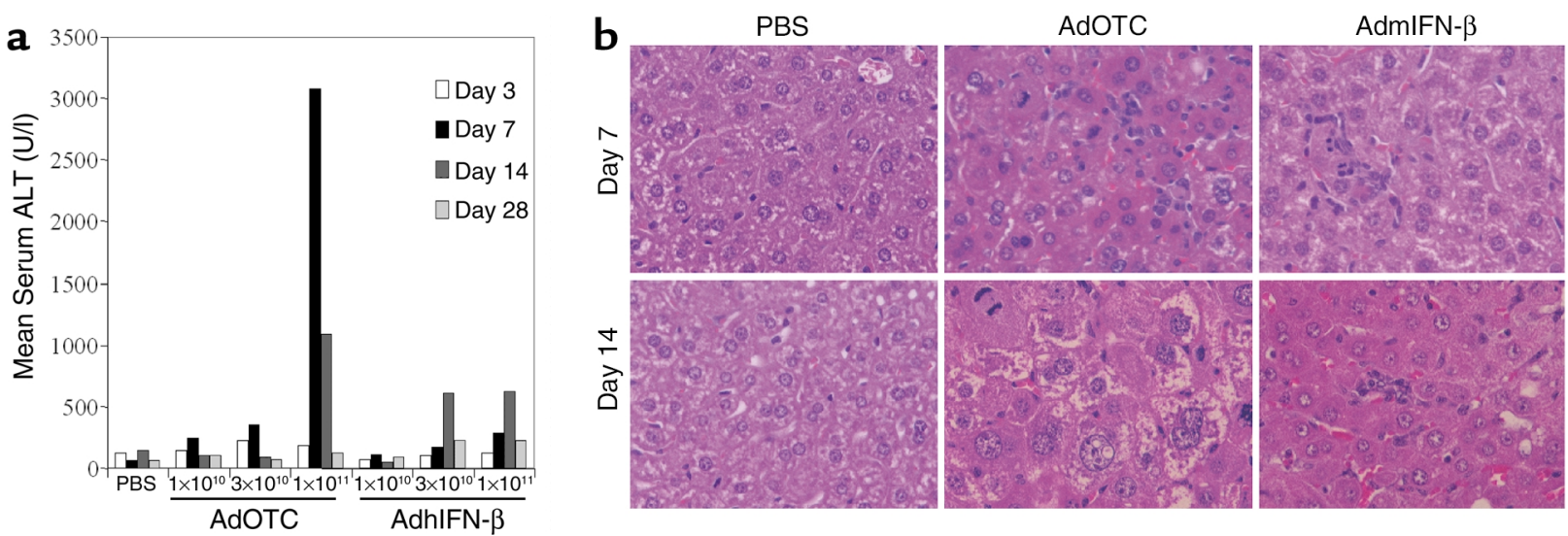

\section{Figure 7}

Liver function tests and histology after H5.110CMVmIFN- $\beta$ treatment. (a) Non-tumor-bearing BALB/c mice were randomized to receive PBS, H5.110CBhOTC (AdOTC), or H5.110CMVmIFN- $\beta$ (AdmIFN- $\beta$ ) via tail vein injections. Animals from each group were sacrificed on days 3,7 , and 14 , at which time serum and livers were harvested. ALT (U/I) from treated animals. $n=5$ per group per time point. (b) Representative sections of liver from animal livers.

to the cytotoxic and cytostatic effects of treatment with recombinant $\mathrm{mIFN}-\beta$ protein in vitro (data not shown) and therefore allowed the evaluation of indirect effects of IFN- $\beta$ in the in vivo model. Five days after tumor inoculation mice were treated with systemic administration of PBS, H5.010CMV $\beta$-gal, or H5.110CMVhIFN- $\beta$. Animals were euthanized 19 days after cancer cell inoculation, and tumors were measured. The results are summarized in Figure $6 \mathrm{~b}$. A response to therapy was observed. H5.010CMV $\beta$-gal treatment resulted in a modest reduction in tumor volume; however, a significant reduction in tumor volume was observed after treatments with H5.110CMVmIFN- $\beta(P<0.0001)$.

Serum levels of mIFN- $\beta$ protein were measured 3 and 14 days after treatment of these mice. No detectable levels of mIFN- $\beta$ protein were observed in the serum of mice treated with PBS or H5.010CMV $\beta$-gal. Mean serum mIFN- $\beta$ protein levels in the H5.110CMVmIFN$\beta$-treated mice was $363 \pm 186 \mathrm{ng} / \mathrm{ml} 3$ days after vector administration. Fourteen days after vector administration, mean serum mIFN- $\beta$ protein levels had fallen to $24.3 \pm 14.4 \mathrm{ng} / \mathrm{ml}$.

Survival studies were performed in the microscopic disease model. $\mathrm{BALB} / \mathrm{c}$ mice were treated with vector administration 5 days after tumor inoculation with CT26 cells (intrasplenic). Treatment groups included PBS and vector controls, along with systemically administered H5.110CMVmIFN- $\beta\left(5 \times 10^{10}\right.$ particles per mouse). An additional treatment group of recombinant mIFN $-\beta(10,000 \mathrm{U} / \mathrm{d}$ intraperitoneally $\times 14$ days $)$ treatment was included. Although recombinant mIFN- $\beta$ resulted in no significant change in survival, H5.110CMVmIFN- $\beta$ resulted in a statistically significant improvement in survival of treated animals $(P<0.01)$ (Figure 6c). All animal mortalities were secondary to tumor burden. Median survival for the PBS, control vector, and recombinant mIFN- $\beta$ treatment groups was 32 , 33 , and 33 days, respectively. Median survival for the H5.110CMVmIFN- $\beta$ treated mice; however, was 50 days.
mIFN- $\beta$ gene therapy is effective in a subcutaneous tumor model. We evaluated mIFN- $\beta$ gene therapy in a subcutaneous tumor model to evaluate if IFN- $\beta$ secreted by transduced hepatocytes could engender a therapeutic response in a distant tumor. Subcutaneous tumors were generated with CT26 cells in BALB/c mice. Five days after tumor inoculation, mice were treated with systemic administration of PBS, H5.010CMV $\beta$-gal, or H5.110CMVhIFN- $\beta$. Animal tumor volumes were measured twice weekly, and the results are summarized in Figure $6 \mathrm{~d}$. Although treatment with the control vector H5.010CMV $\beta$ gal resulted in a modest reduction in tumor volume, a significant reduction in tumor volume was observed after treatment with H5.110CMVmIFN- $\beta$ $(P<0.05)$. The response was less than that observed in the liver metastases model, indicating that this therapy is less effective when IFN- $\beta$ production is not in proximity to the tumors.

mIFN- $\beta$ gene therapy in a murine colorectal cancer liver metastases model activates $N K$ cells. We sought to determine the mechanisms of action of mIFN- $\beta$ in this model. Consistent with the observation that CT26 cells are resistant to the cytotoxic effects of mIFN- $\beta$ in vitro, we observed no significant apoptotic response in the CT26 tumors after H5.110CMVmIFN- $\beta$ treatment (data not shown). We therefore evaluated the contribution of cytotoxic T-lymphocytes, NK cells, and macrophage activation in this model.

To assess the contribution of lymphocytes, 5 days after intrahepatic injection with CT26 cells, athymic nude mice were treated with systemic administration of PBS, H5.010CMVßgal, or H5.110CMVhIFN- $\beta$. Animals were euthanized 19 days after cancer cell inoculation, and tumors were measured. As demonstrated in Figure 8a, H5.110CMVmIFN- $\beta$ was equally effective in nude mice as in $\mathrm{BALB} / \mathrm{c}$ mice, indicating a limited $\mathrm{T}$ cell contribution to the therapeutic response in this model. To assess the role of macrophage activation, a similar experiment was performed in which macrophage deple- 


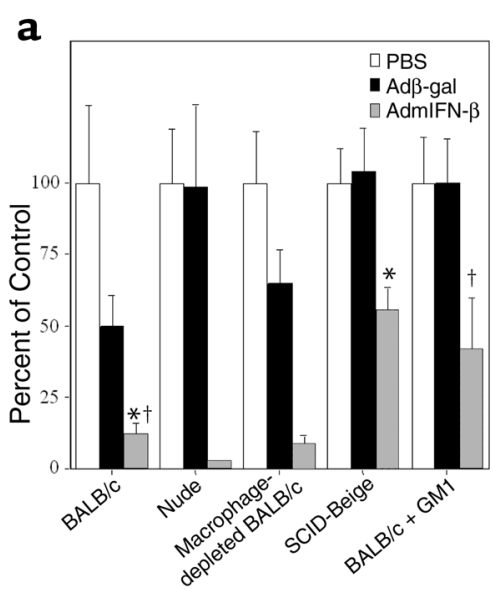

b

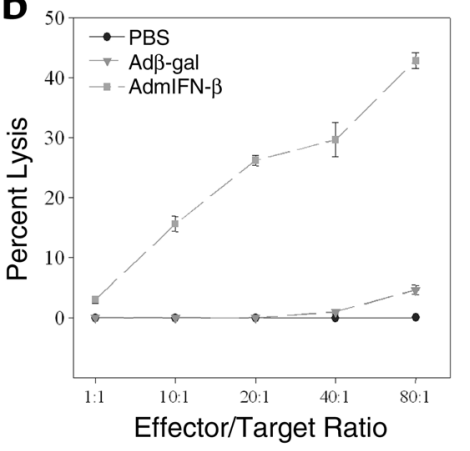

Figure 8

H5.110CMVhIFN- $\beta$ treatment increases NK cell activity, and inhibition of tumor growth by $\mathrm{H} 5.110 \mathrm{CMVhIFN}-\beta$ treatment is partially dependent on NK cell activity but not on T cell or macrophage activity. (a) CT26 cells were injected directly in the livers of mice. Five different mouse groups were evaluated: BALB/c mice, nude mice deficient in T cells, BALB/c mice depleted of macrophages with DMDP, SCID-Beige mice deficient in lymphocytes and NK cells, and BALB/c mice depleted of NK cells with the NK-blocking antibody. On day 5 , mice were randomized to receive PBS, H5.010CMV $\beta$-gal, or H5.110CMVhIFN- $\beta$ via tail vein injection. On day 19 , livers were harvested for tumor volume measurement. Data are presented as percent of control, with control being the PBS group for the specific mouse strain or depletion. $\left(n=10\right.$ per group). ${ }^{*} P<0.05$, BALB $/ c$ AdmIFN- $\beta$ vs. SCID-Beige AdmIFN- $\beta$; $+P<0.05$, BALB $/ c$ AdmIFN- $\beta$ vs. BALB/ + GM1 AdmIFN- $\beta$. (b) NK cells harvested from the livers and spleens of treated animals were cultured in RPMI 1640 (Life Technologies Inc.) supplemented with $12.5 \%$ filtered serum from the sacrificed animals at $37^{\circ} \mathrm{C}$ for 48 hours. NK cell activity was determined using a ${ }^{51} \mathrm{chromium}$ release assay. Percentage cytotoxicity was calculated as (experimental release spontaneous release $) /($ total release - spontaneous release $) \times 100$.

tion with liposome-encapsulated dichloromethylene diphosphonate (DMDP) failed to abrogate the response H5.110CMVmIFN- $\beta$, indicating a limited role of macrophages in this model (Figure 8a).

The therapeutic effect of H5.110CMVmIFN- $\beta$ was significantly abrogated, however, in BALB/c mice pretreated with an NK-blocking antibody and in SCIDBeige mice (which lack NK cells). Data for all the treatment groups are presented in Figure $8 \mathrm{a}$ as percent of control (control being the tumor size in the specific strain of animal and depletion method treated with PBS). As shown, treatment with $\mathrm{H} 5.110 \mathrm{CMVmIFN}-\beta$ in BALB/c mice resulted in an $88 \%$ reduction in tumor volume compared to PBS control. Treatment in $\mathrm{BALB} / \mathrm{c}$ mice pretreated with an NK-blocking antibody and SCID/Beige mice, howev- er, resulted in only a $58 \%$ and $44 \%$ reduction in tumor volume respectively.

To assess the effect of mIFN- $\beta$ gene therapy on NK cell activity, NK cells were isolated from treated animals 3 days after H5.110CMVmIFN- $\beta$ treatment. NK cell activity was determined using a ${ }^{51} \mathrm{chromi}-$ um-release assay as previously described (32). As demonstrated in Figure 8b, while NK cells isolated from PBS and control vector treated mice had little or no activity in this assay, $\mathrm{NK}$ cells isolated from H5.110CMVmIFN- $\beta$ treated mice demonstrated significant lysis of the target cells. $m I F N-\beta$ gene therapy does not effect vessel counts in a murine colorectal cancer liver metastases model. While the data indicates that NK cell activation contributes to the therapeutic activity of H5.110CMVmIFN- $\beta$ in this model, other factors are likely contributing to this effect. To assess whether treatment results in the inhibition of angiogenesis, we performed tumor vessel counts after treatment. CT26 hepatic tumors in BALB/c mice were evaluated 14 days after treatment with $100 \mu$ of PBS, $5 \times 10^{10}$ particles of H5.010CMV $\beta$-gal, or $5 \times 10^{10}$ particles of H5.110CMVmIFN- $\beta$. Immunohistochemical staining for CD31 (a cell surface molecule found on endothelial cells) was performed on tumor specimens, and vessel counts were performed. As demonstrated in Figure 9, no significant reduction in tumor vessel counts was observed after H5.110CMVmIFN- $\beta$ treatment compared with PBS and vector controls.

\section{Discussion}

Colorectal cancer is a significant cause of morbidity and cancer-related deaths in the US. A majority of patients succumb to colorectal cancer with multiple metastases predominantly in the liver. A clinical impact on this disease requires a systemic or regional therapy directed at all the liver metastases. Recombinant adenoviral vectors hold promise in the field of cancer gene therapy, but at the present time adenoviral vectors have been limited mostly to locally directed therapies for diseases such as glioblastoma, mesothelioma, and head and neck cancer (3). To expand the scope of cancer gene therapy we must develop schemas to treat regional or systemic metastat-

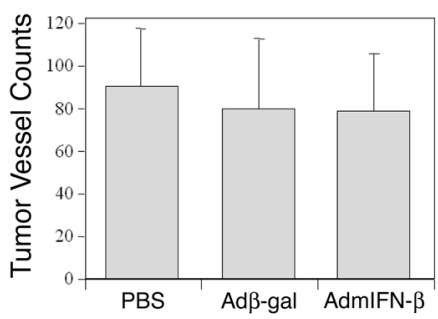

Figure 9

No significant reduction in tumor blood vessels after $\mathrm{H} 5.110 \mathrm{CMVmIFN}-\beta$ treatment in a murine colorectal cancer liver metastases model. CT26 cells were injected directly in the livers of BALB/c mice. On day 5, mice were randomized to receive PBS, H5.010CMV $\beta$-gal, or H5.110CMVhIFN- $\beta$ via tail vein injection. Animals were sacrificed on day 19 and the livers harvested. Immunohistochemical staining for CD31 (endothelial cells) was performed on frozen sections of tumor. The number of microvessels (independent CD31-positive structures) was quantified using NIH Image 1.60 software, and the mean number of vessels per $0.159-\mathrm{mm}^{2}$ field was determined. Five random $0.159-\mathrm{mm}^{2}$ fields at $\times 100$ magnification were captured for each tumor. 
ic disease. The strategy we have presented uses current vector technology along with IFN- $\beta$ therapy. The systemic administration of our vector and the transduction of hepatocytes resulted in sustained secretion of hIFN- $\beta$ at high local concentrations. Administration of 10,000 units of recombinant protein intraperitoneally resulted in peak serum and hepatic concentrations at 1 hour, but levels had fallen to undetectable at six hours. These results are consistent with previous pharmacokinetic analyses after subcutaneous and intramuscular injection of recombinant IFN- $\beta$ (24). The intraperitoneal administration of recombinant IFN- $\beta$ protein resulted in slightly higher peak serum levels, however all routes of administration resulted in undetectable IFN- $\beta$ serum levels within several hours. By utilizing adenoviral vectors we were able to generate higher IFN- $\beta$ levels at higher doses of vector and more persistent local expression at both lower and higher vector doses. This IFN- $\beta$ gene therapy strategy may circumvent potential pitfalls of both cancer gene therapy strategies and parental IFN- $\beta$ protein, specifically 1 ) the inability to transduce a significant number of cancer cells with our current gene therapy strategies; and 2 ) the inability to deliver IFN- $\beta$ protein in a fashion that will generate peritumoral concentrations for an extended duration.

Given the species specificity of IFN- $\beta$, the mechanism of the antitumoral effect in our xenograft model is likely related to a direct antiproliferative and/or cytotoxic effect of hIFN- $\beta$ on human cancer cells. The extensive and rapid onset of apoptosis in the tumors within 48 hours after H5.110CMVhIFN- $\beta$ administration is consistent with an induction of apoptosis by hIFN- $\beta$ within the human cancer cells. The lack of a measurable effect of H5.110CMVhIFN- $\beta$ on a murine colorectal cancer cell line in an athymic nude mouse model and the limited cross-species reactivity of this cytokine indicate a direct interaction of human IFN- $\beta$ on the human tumor cells (and do not support a role of T cells, NK cells, macrophage activation, or the inhibition of angiogenesis in the xenograft model with the human IFN- $\beta$ vector). Inhibition of angiogenesis has previously been demonstrated after more than 5 days of exposure to hIFN- $\beta$, but it appears a less likely explanation of the responses in our model given the time course of the observed response (19). The induction of apoptosis and tumor regression observed in the present study was observed within 2 days of treatment and did not allow for analysis of vessel counts.

Type I IFNs exert their response via a common receptor with two subunits (12). Interaction with their receptor results in phosphorylation of receptor associated tyrosine kinases (Jak-1 and Tyk-2) (33). The activation of this pathway in vitro was confirmed in these cells after treatment. Additionally, induction of the proapoptotic mediators TRAIL and Bak was observed in vitro. Both these apoptotic mediators represent potential pathways in which IFN- $\beta$ may induce its apoptotic response.

The evaluation of H5.110CMVmIFN- $\beta$ in a syngeneic model enabled us to evaluate indirect mechanisms of action that may contribute to therapeutic responses clinically. In the syngeneic model, induction of apoptosis was not observed in the CT26 tumors. Vessel counts in the H5.110CMVmIFN- $\beta$-treated tumors demonstrated no significant differences from controls, indicating inhibition of angiogenesis did not play a major role in this effect. Effects on angiogenesis not measured by vessel counts, however, may have contributed to this response. Our data indicate that NK cell activation contributed to the therapeutic response observed, whereas macrophage and $T$ cell activation appear less likely to be major contributors of the therapeutic response in our model. This indirect mechanism of action may be relevant in evaluation of human clinical trials. The induction of a cytokine response, including type I IFNs, after administration of replication defective and semicompetent adenoviral vectors has been evaluated $(6,34-39)$. The nonspecific induction of cytokines is an early response (6-24 hours) to vector administration $(38,39)$, and, in the present study, no observable elevations of serum levels of mIFN- $\beta$ protein were found 3 days after control vector administration. Nevertheless, the nonspecific induction of cytokines, including type I IFNs, may contribute to the limited response of tumors to control vectors and partially contribute to the antitumor activity of replication-restricted adenoviral vectors (6).Although we observed limited toxicity in our xenograft experiments, questions concerning potential toxicity of this hIFN- $\beta$ therapy remain. Our data from administration of adenoviral vectors encoding for murine IFN- $\beta$ indicate that systemic toxicities would occur at the highest vector doses. These systemic toxicities may limit our ability to generate sufficient local levels of hIFN- $\beta$ to induce an anticancer response. However, the data in an immune-competent mouse with murine IFN- $\beta$ demonstrate that doses that are tolerated can result in a therapeutic response. Also, the doseresponse data for the hIFN- $\beta$ vector indicate that significant antitumor responses can be obtained with a broad range of vector doses, including a dose that resulted in liver hIFN- $\beta$ levels, but low to undetectable systemic levels. Measurements of mIFN- $\beta$ after vector administration demonstrated similar kinetics of gene expression; however, length of expression was reduced in the immune-competent mice treated with H5.110CMVmIFN- $\beta$. This reduction in protein expression may be secondary to immune-mediated effects on duration of viral expression or direct antiviral effects of mIFN- $\beta$ against viral gene expression. Further information about toxicity may be garnered from studies of hIFN- $\beta$ in nonhuman primate experiments. As with most cytotoxic therapies, there is a potential of generating IFN-resistant clones from this therapy, ultimately resulting in treatment failure. As demonstrated in the syngeneic model, however, significant therapeutic effects can be observed in tumor cells that are relatively resistant to IFN- $\beta$ in vitro. We have demonstrated the efficacy of a systemically administered regional cancer gene therapy strategy for metastatic colorectal cancer. 
This therapy resulted in suppression of tumor growth, tumor regression, and long-term survival in an established orthotopic colorectal cancer liver metastases model. The micrometastatic model has clinical correlation to the adjuvant setting for therapy. A common clinical presentation is one in which patients present with disease localized to the colon, but are at high risk for the development of liver metastases secondary to occult micrometastatic disease. Treatment in the adjuvant setting offers the best opportunity for cure. Of interest, treatment with the standard chemotherapeutic used for colorectal cancer, 5 -fluorouracil $(100 \mathrm{mg} / \mathrm{kg})$, in this micrometastatic model failed to result in cure (data not shown). It is encouraging that the therapeutic responses were observed not only in a micrometastatic model but also in a gross disease model. This model mirrors the clinical presentation of clinically evident gross metastatic disease to the liver.The data presented here provide encouraging evidence that supports a regional gene therapy strategy, specifically demonstrating that liver metastases can be treated with the systemic intravascular administration of AdhIFN- $\beta$. The large patient population with liver metastases and limited effective therapeutic modalities represents a potential target for this form of therapy.

\section{Acknowledgments}

The authors thank Sarah Haecker for support of the animal studies, Yi Zhang for assistance with the macrophage depletion, and Lan Zhou for assistance with statistical analysis. This study was partially supported by a grant from the American Cancer Society and the University of Pennsylvania Center for Molecular Studies in Digestive and Liver Disease Morphology Core (NIH Center Grant P30 DK50306 to F.R. Spitz).

1. Greenlee, R., Murray, T., Bolden, S., and Wingo, P.A. 2000. Cancer statistics, 2000. CA Cancer J. Clin. 50:7-33.

2. Fong, Y., Kemeny, N., Paty, P., Blumgart, L.H., and Cohen, A.M. 1996. Treatment of colorectal cancer: hepatic metastasis. Semin. Surg. Oncol. 12:219-252.

3. Roth, J., and Cristiano, R. 1997. Gene therapy for cancer: what have we done and where are we going? J. Natl. Cancer Inst. 89:21-39.

4. Roth, J., et al. 1998. Gene therapy for non-small cell lung cancer: a preliminary report of a phase I trial of adenoviral p53 gene replacement. Semin. Oncol. 25:33-37.

5. Clayman, G., et al. 1998. Adenovirus-mediated p53 gene transfer in patients with advanced recurrent head and neck squamous cell carcinoma. Clin. Oncol. 16:2221-2232.

6. Alemany, R., Balague, C., and Curiel, D. 2000. Replicative adenoviruses for cancer therapy. Nat. Biotechnol. 18:723-727.

7. Steinwaerder, D., Carlson, C., and Lieber, A. 2000. DNA replication of firstgeneration adenovirus vectors in tumor cells. Hum. Gene Ther. 11:1933-1948.

8. Yoon, S., et al. 2000. An oncolytic herpes simplex virus type 1 selectively destroys diffuse liver metastases from colon carcinoma. FASEB $\mathrm{J}$. 14:301-311.

9. Steinwaerder, D., et al. 2001. Tumor-specific gene expression in hepatic metastases by a replication-activated adenovirus vector. Nat. Med. 7:240-243.

10. Grace, M., et al. 1999. The use of laser scanning cytometry to assess depth of penetration of adenovirus p53 gene therapy in human xenograft biopsies. Am. J. Pathol. 155:1869-1878.

11. Topf, N., Worgall, S., Hackett, N.R., and Crystal, R.G. 1998. Regional 'prodrug' gene therapy: intravenous administration of an adenoviral vector expressing the $E$. coli cytosine deaminase gene and systemic administration of 5-fluorocytosine suppresses growth of hepatic metastasis of colon carcinoma. Gene Ther. 5:507-513.

12. Lengyel, P. 1982. Biochemistry of interferons and their actions. Annu. Rev.
Biochem. 51:251-282.

13. Johns, T., et al. 1992. Antiproliferative potencies of interferons on melanoma cell lines and xenografts: higher efficacy of interferon beta. $J$. Natl. Cancer Inst. 84:1185-1190.

14. Shimizu, M., et al. 1997. Effect on colon cancer cells of human interferonbeta gene entrapped in cationic multilamellar liposomes. Biochem. Mol. Biol. Int. 644:1235-1243.

15. Wadler, S., Wersto, R., Weinberg, V., Thompson, D., and Schwartz, E.L. 1990. Interaction of fluorouracil and interferon in human colon cancer cell lines: cytotoxic and cytokinetic effects. Cancer Res. 50:5735-5739.

16. Ohwada, S., et al. 1996. Interferon potentiates antiproliferative activity of CPT-11 against human colon cancer xenografts. Cancer Lett. 110:149-154.

17. Sidky, Y., and Borden, E. 1987. Inhibition of angiogenesis by interferons: effects on tumor and lymphocyte-induced vascular responses. Cancer Res. 47:5155-5161.

18. Dvorak, H., and Gresser, I. 1989. Microvascular injury in pathogenesis of interferon-induced necrosis of subcutaneous tumors in mice. J. Natl. Cancer Inst. 81:497-502.

19. Singh, R., et al. 1995. Interferons alpha and beta down-regulate the expression of basic fibroblast growth factor in human carcinomas. Proc. Natl. Acad. Sci. USA. 92:4562-4566.

20. Belardelli, F., and Gresser, I. 1996. The neglected role of type I interferon in the T-cell response: implications for its clinical use. Immunol. Today. 17:369-372.

21. Tough, D., Borrow, P., and Sprent, J. 1996. Induction of bystander T cell proliferation by viruses and type I interferon in vivo. Science. 272:1947-1950. 22. Dong, Z., et al. 1998. Supp

ression of tumorigenicity and metastasis in murine UV-2237 fibrosarcoma cells by infections with a retroviral vector harboring the interferon-beta gene. Cancer Immunol. Immunother. 46:137-146.

23. Ferrantini, M., et al. 1994. IFN-alpha 1 gene expression into a metastatic murine adenocarcinoma (TS/A) results in CD8+ T cell-mediated tumor rejection and development of antitumor immunity. Comparative studies with IFN-gamma-producing TS/A cells. J. Immunol. 153:4604-4615.

24. Salmon, P., Le Cotonnec, J., Galazka, A., Abdul-Ahad, A., and Darragh, A. 1996. Pharmacokinetics and pharmacodynamics of recombinant human interferon-beta in healthy male volunteers. J. Interferon Cytokine Res. 16:777-781.

25. Fierlbeck, G., et al. 1996. Pharmacodynamics of recombinant IFN-beta during long-term treatment of malignant melanoma. J. Interferon Cytokine Res. 16:777-781.

26. Morikawa, K., et al. 1988. Influence of organ environment on the growth, selection, and metastasis of human colon carcinoma cells in nude mice. Cancer Res. 48:6863-6871.

27. Qin, X. 1998. Interferon-beta gene therapy inhibits tumor formation and causes regression of established tumors in immune-deficient mice. Proc. Natl. Acad. Sci. USA. 95:14411-14416.

28. Davis, B.M., Koc, O.N., Lee, K., and Gerson, S.L. 1996. Current progress in the gene therapy of cancer. Curr. Opin. Oncol. 8:499-508.

29. Kasai, M., Iwamori, M., Nagai, Y., Okumura, K., and Tada, T. 1980. A glycolipid on the surface of mouse natural killer cells. Eur. J. Immunol. 10:175-180.

30. van Rooijen, et al. 1988. In vitro and in vivo elimination of macrophage tumor cells using liposome-encapsulated dichloromethylene diphosphonate. Virchows Arch. B Cell Pathol. Incl. Mol. Pathol. 54:241-245.

31. Gavrieli, Y., Sherman, Y., and Ben-Sasson, S. 1992. Identification of programmed cell death in situ via specific labeling of nuclear DNA fragmentation. J. Cell Biol. 119:493-501.

32. Yu, Y., et al. 1996. The role of Ly49A and 5E6(Ly49C) molecules in hybrid resistance mediated by murine natural killer cells against normal $\mathrm{T}$ cell blasts. Immunity. 4:67-76.

33. Schindler, C., and Darnell, J.E.J. 1995. Transcriptional responses to polypeptide ligands: the JAK-STAT pathway. Annu. Rev. Biochem. 64:621-651.

34. Dong, Z., Yang, X., and Fidler, I. 1997. Neutralization of endogenous interferon-beta increases the efficiency of adenoviral vector-mediated gene transduction. J. Interferon Cytokine Res. 17:401-407.

35. Shiroki, K., Kato, H., and Kawai, S. 1990. Tandemly repeated hexamer sequences within the beta interferon promoter can function as an inducible regulatory element in activation by the adenovirus E1B 19-kilodalton protein. J. Virol. 64:3063-3068.

36. Feigenblum, D., Walker, R, and Schneider, R. 1998. Adenovirus induction of an interferon-regulatory factor during entry into the late phase of infection. J. Virol. 72:9257-9266.

37. Nielsch, U., Pine, R., Zimmer, S., and Babiss, L.E. 1992. Induced expression of the endogenous beta interferon gene in adenovirus type 5-transformed rat fibroblasts. J. Virol. 66:1884-1890.

38. Schnell, M., et al. 2001. Activation of innate immunity in nonhuman primates following intraportal administration of adenoviral vectors. Mol. Ther. 3:708-722.

39. Zhang, Y., et al. 2001. Acute cytokine response to systemic adenoviral vectors in mice is mediated by dendritic cells and macrophages. Mol. Ther. 3:697-707. 